\title{
DETERMINAÇÃo DE NITRATO E NITRITO EM CHÁS DE PELES DE PESCADOS EMPREGAdOS PARA TRATAMENTO DE ASMA BRÔNQUICA NA REGIÃO SUL DO RIO GRANDE DO SUL
}

\author{
Ademir Larrea Bastos, Ana Luiza Muccilo Baisch, Leonor Almeida de Souza Soares, Janaína Fernandes de Medeiros \\ Burkert e Eliana Badiale Furlong* \\ Fundação Universidade Federal do Rio Grande, CP 474, 96201-900 Rio Grande - RS, Brasil
}

Recebido em 7/3/05; aceito em 6/1/06; publicado na web em 5/5/06

\begin{abstract}
NITRATE AND NITRITE DETERMINATION IN FISH SKIN TEAS EMPLOYED FOR ASTHMA TREATMENT IN THE SOUTHERN REGION OF RIO GRANDE DO SUL. The objective of this paper was to determine nitrate and nitrite anions in toasted fish skin tea, which the population of southern Rio Grande do Sul believes to have pharmacological properties for trating asthma. Two methods were compared, an official and one described by Guozhen et al., that has the advantage of not needing reduction of nitrate to nitrite on a Cd column. The samples were the skin of the fish species Balistes capriscus (peixe porco) and Menticirrhus littoralis (papa-terra), both crude and toasted, as traditionally used. The method of Guozhen et al. was used due to its performance (detection limit $0.005 \mu \mathrm{mol} / \mathrm{L} \mathrm{NO}_{3}{ }^{-}$and $0.02 \mu \mathrm{mol} / \mathrm{L}-\mathrm{NO}_{2}{ }^{-}$and mean recuperation of 100 and $97 \%$ respectively for each anion) and results similar to those of the official methods under conditions used by the population, the estimated daily intake, of the teas is equivalent to 0.03 to $0.05 \mathrm{mg}$ of nitrate and 0.007 to $0.014 \mathrm{mg}$ of nitrite. These values are in accord with safety recommendations and don't represent a health risk.
\end{abstract}

Keywords: nitrate; nitrite; fish skin.

\section{INTRODUÇÃ̃o}

Na região sul do Rio Grande do Sul segundo dados fornecidos pelo CEPERG/RS ${ }^{1}$ (de 1999 a 2001), as espécies Balistes capriscus (peixe porco) e Menticirrhus littoralis (papa-terra) são pouco valorizadas industrialmente, sendo utilizadas para fabricação de subprodutos, como farinha e silagem.

A utilização de chás preparados com peles torradas de peixe porco e papa-terra pela população da região sul do Rio Grande do Sul, para tratamento de asma brônquica, chamou a atenção de pesquisadores da Fundação Universidade Federal do Rio Grande, no sentido de buscar uma forma de conferir caráter científico a um conhecimento popular. Foram desenvolvidos vários experimentos biológicos indicando que o efeito vasodilatador pode estar associado à presença de nitrato/nitrito nos chás das peles de pescado ${ }^{2}$. Cavalli $^{2}$ demonstrou experimentalmente o efeito sobre a asma brônquica submetendo cobaias acometidas de crise asmática ao extrato de pele torrada de peixe porco, que reverteu o quadro pela simples aspiração do vapor. A partir desta constatação iniciou-se a busca por um procedimento analítico que pudesse quantificar a presença destes ânions com segurança, que fosse rápido, acessível e gerasse o mínimo de resíduos tóxicos ao final das determinações.

Diferentes autores atribuem a reversão do quadro de broncoconstrição ao óxido nítrico (NO), pois este estimula a enzima guanilato ciclase que eleva os níveis de GMPc, causando relaxamento da musculatura vascular lisa ou ativando canais de $\mathrm{K}^{+}$dependentes de $\mathrm{Ca}^{++}$, o que leva a uma hiperpolarização das células da musculatura lisa independente dos níveis de $\mathrm{GMPc}^{2-5}$.

$\mathrm{O}$ NO, em humanos, pode ser sintetizado a partir de alguns mecanismos envolvendo reações enzimáticas. Outra forma de

*e-mail: dqmebf@furg.br sintetizá-lo é através dos íons nitrato e nitrito administrados como medicação ou pela dieta. No caso de via oral, pela ação de bactérias na boca ou pela ação de enzimas digestivas, o nitrato pode ser rapidamente convertido a nitrito, que é reativo sob condições ácidas no estômago, podendo formar óxido nítrico ${ }^{2-5}$. Além desta possibilidade, o nitrito pode reagir com uma variedade de compostos orgânicos, especialmente aminoácidos, e formar substâncias cancerígenas, como as nitrosaminas ${ }^{6,7}$.

Grande número de metodologias analíticas têm sido propostas para determinação de íons nitrato e nitrito, incluindo a associação de procedimentos cromatográficos, espectrofotométricos e potenciométricos $^{8-10}$. Os métodos espectrofotométricos são freqüentemente empregados, pelos baixos limites de detecção, pela rapidez, simplicidade e versatilidade de reagentes cromogênicos ${ }^{8,11}$.

Dentre os procedimentos mais conhecidos destaca-se o de Griess, desenvolvido em 1879, uma técnica simples e que se tornou oficial para quantificação de nitratos e nitritos, sob a forma do íon nitrito, após reação com sulfanilamida e etilenodiamina. A principal desvantagem é a necessidade de se empregar colunas de cádmio envelopado em cobre para redução do nitrato e uma solução de cloreto de cádmio para extração dos íons de amostras sólidas. A coluna de redução precisa ser regenerada após a passagem de algumas amostras e desta regeneração resultam resíduos que precisam ser descartados, bem como o próprio amalgama depois de um período de uso $^{8,9,12}$.

Outro método espectofotométrico foi padronizado por Guozhen et al. ${ }^{11}$ para ser empregado em laboratórios com infraestrutra simples, pois possui as vantagens de não requerer emprego de colunas redutoras e de ser sensível a quantidades traço dos íons nitrato e nitrito, com um erro máximo de $5 \%$ na determinação, causado pela presença de outros íons interferentes. A tendência atual é disponibilizar procedimentos acessíveis e que gerem menos resíduos tóxicos para descarte. Outro aspecto considerado neste trabalho foi disponibilizar uma metodologia confiável, dentro deste cuidado com o tipo de resíduo produzido durante a determinação, e 
que permitisse avaliar os riscos de contaminação crônica que a população possa estar sendo submetida por suas próprias crenças.

Estes fatos nortearam o presente trabalho, que visou determinar íons nitrato e nitrito presentes em chás de peles torradas de Balistes capriscus e Menthicirrus litorallis, para estimar os riscos de contaminação pelo consumo destes no tratamento de asma brônquica. Para isto comparam-se duas metodologias, a oficial e outra descrita por Gouzhen et al. ${ }^{11}$.

\section{PARTE EXPERIMENTAL}

\section{Equipamentos}

Foram utilizados balança Analítica Gilbertini (0,0000 a 200,0000 g), espectrofotômetro UV/Vis, Varian, modelo Cary 100 e estufa com circulação de ar, marca Quimis.

\section{Reagentes e soluções}

Empregou-se solução extratora $1\left(\mathrm{AOAC}^{14}\right): 50 \mathrm{~g} \mathrm{de} \mathrm{CdCl}_{2}, 50 \mathrm{~g}$ de $\mathrm{BaCl}_{2}$ e $1 \mathrm{~mL}$ de $\mathrm{HCl} 18 \mathrm{M}$; solução extratora 2: 2,5 g de $\left(\mathrm{NH}_{4}\right)_{2} \mathrm{SO}_{4}$ com ajuste de $\mathrm{pH}$ para 8,5 com solução de amônia diluída $(30 \%)$ completando o volume para $1 \mathrm{~L}$ com água; solução tampão de cloreto de amônio pH 9,6:5 g de $\mathrm{NH}_{4} \mathrm{Cl}$ em $50 \mathrm{~mL}$ de água, ajustando o $\mathrm{pH}$ com $\mathrm{NH}_{4} \mathrm{OH}$ concentrado, elevando o volume para $100 \mathrm{~mL}$ com água; solução estoque de nitrito de potássio $5000 \mu \mathrm{M}$; solução estoque de nitrato de potássio $4600 \mu \mathrm{M}$; solução de sulfanilamida (R1): $50 \mathrm{~mL}$ de $\mathrm{HCl}$ concentrado diluído em $300 \mathrm{~mL}$ de água, acrescidos $5 \mathrm{~g}$ do reagente sulfanilamida para volume de $500 \mathrm{~mL}$; solução de dicloroidrato de etilenodiamina (R2): $0,5 \mathrm{~g}$ de dicloroidrato detilenodiamina dissolvidos em $500 \mathrm{~mL}$ de água; solução de $\rho$-nitroanilina $10 \mathrm{mM}$ em ácido clorídrico $2 \mathrm{M}$; solução de $\alpha$-naftilamina $10 \mathrm{mM}$ em ácido clorídrico $1 \mathrm{M}$; solução de resorcinol $2 \%(\mathrm{~m} / \mathrm{v})$ e solução $0,05 \mathrm{M}$ de brometo de cetiltrimetilamônio (CTMAB).

As soluções cromogênicas foram preparadas no máximo $24 \mathrm{~h}$ antes do uso.

Os sais para preparação das soluções estoque de nitrato e nitrito foram da Merck, o ácido clorídrico e os demais sais e reagentes cromogênicos foram da Synth.

\section{Coleta e preparo das amostras}

As amostras da espécie Balistes capriscus (peixe porco) foram coletadas em uma indústria pesqueira, nos meses de julho e agosto de 2003, e as amostras de Menticirrhus litoralis (papa-terra), no entreposto pesqueiro da cidade, no mesmo período. Os espécimes amostrados foram indivíduos adultos, sem distinção de sexo.

Os espécimes de papa-terra foram escamados e fileteados separando a pele do músculo. As peles foram homogeneizadas utilizando moedor manual de rosca sem fim. As amostras de peixe porco tiveram a pele separada do músculo, porém a maneira como as escamas aderem à pele não permitiram a perfeita escamação. Para homogeneizá-las foi empregado um moedor elétrico para romper a resistência ao corte. As porções homogeneizadas foram armazenadas sob congelamento $\left(-18{ }^{\circ} \mathrm{C}\right)$ até o momento das determinações analíticas.

Uma parte das peles homogeneizadas dos dois pescados foi separada para ser tratada de forma similar ao procedimento popular de preparo dos chás para tratamento de asma brônquica. Isto consistiu em secá-las em estufa a temperaturas de 130 ou $160{ }^{\circ} \mathrm{C}$ por 30 ou 60 min para cada temperatura, macerando-as posteriormente com auxílio de graal e pistilo.

\section{Preparo das amostras analíticas}

A $5 \mathrm{~g}$ de cada amostra foram adicionados $100 \mathrm{~mL}$ da solução extratora 1 e $100 \mathrm{~mL}$ de água, agitando-as durante $1 \mathrm{~h}$ com agitador magnético à $30^{\circ} \mathrm{C}$. Em seguida, foram adicionados à mistura $20 \mathrm{~mL}$ de $\mathrm{NaOH} 2,5 \mathrm{M}$, diluindo com água até $250 \mathrm{~mL}$ e filtrando posteriormente. Foram colocados $10 \mathrm{~mL}$ do tampão cloreto de amônio $\mathrm{pH}$ 9,6 em um balão volumétrico de $100 \mathrm{~mL}$ diluindo com a solução de amostra filtrada. O mesmo procedimento foi empregado com a solução extratora 2 .

As peles secas $(5 \mathrm{~g})$ nas duas temperaturas foram homogeneizadas e submetidas a refluxo por 30 ou $60 \mathrm{~min}$ com $100 \mathrm{~mL}$ de água.

\section{Metodologia oficial para determinação de nitrato e nitrito}

\section{Rendimento das colunas redutoras de cádmio}

Para determinação do rendimento da etapa de redução do nitrato a nitrito, colunas plásticas de $15 \mathrm{~cm}$ de comprimento e $1 \mathrm{~cm}$ de d.i. foram preenchidas por amálgama, constituído por grãos de cádmio tratados com solução cúprica (cádmio envelopado com cobre).

Foram transferidos $100 \mathrm{~mL}$ de padrões de $10 \mathrm{mM}$ de $\mathrm{NO}_{3}^{-}$, $10 \mu \mathrm{M}$ de $\mathrm{NO}_{2}{ }^{-}$e água (branco) para provetas acrescidos de $2 \mathrm{~mL}$ de $\mathrm{NH}_{4} \mathrm{Cl}(25 \%)$. De cada uma das soluções foram eluídos $70 \mathrm{~mL}$ pelas colunas de cádmio que foram descartados. Os $30 \mathrm{~mL}$ restantes também foram eluídos pelas colunas. Dos eluatos foram retiradas alíquotas de $5 \mathrm{~mL}$ as quais foram adicionadas de $100 \mu \mathrm{L}$ da solução de sulfanilamida (R1) e $100 \mu \mathrm{L}$ da solução de N-naftil etilenodiamina (R2) sob agitação. Após 10 min foram realizadas as leituras das transmitâncias das misturas a $543 \mathrm{~nm}$.

Do padrão de $10 \mu \mathrm{M}$ de $\mathrm{NO}_{2}{ }^{-}$preparado foi retirado uma alíquota de $5 \mathrm{~mL}$, sem passar pela coluna (padrão de referência), sendo a transmitância determinada em $543 \mathrm{~nm}$ empregando-se cubetas de 1 e $5 \mathrm{~cm}$, respectivamente, para nitrato e nitrito.

\section{Curvas padrão para nitrato e nitrito}

Foi preparada uma solução trabalho (ST) de nitrito de potássio $250 \mu \mathrm{M}$. Desta foram retiradas alíquotas para o preparo dos padrões, cujas concentrações variavam entre 0,25 e $2,5 \mu \mathrm{M}$. As soluções padrões de nitrato de potássio $(0,25$ a $15 \mu \mathrm{M})$ foram preparadas e previamente eluídas pelas colunas redutoras, conforme o procedimento descrito para o teste de recuperação. Nas alíquotas dos padrões foram adicionados $1 \mathrm{~mL}$ dos reativos $\mathrm{R} 1 \mathrm{e} \mathrm{R} 2$, sendo as transmitâncias determinadas após 10 min a $543 \mathrm{~nm}$ em cubetas de 1 e $5 \mathrm{~cm}$, respectivamente.

\section{Redução de nitrato a nitrito}

Para redução do nitrato a nitrito as soluções de amostras e padrão foram passadas pelas colunas de cádmio com rendimento previamente determinado para este experimento.

\section{Determinação de nitrito em amostras analíticas}

Foram tomados $5 \mathrm{~mL}$ dos extratos das amostras $100 \mu \mathrm{L}$ da solução R1, $100 \mu \mathrm{L}$ da solução R2 e a mistura foi agitada em banho ultrassônico. As transmitâncias das soluções foram determinadas após $10 \mathrm{~min}$ a $543 \mathrm{~nm}$.

\section{Determinação de nitrato em amostras analíticas}

Foram tomados $15 \mathrm{~mL}$ dos extratos das amostras e $200 \mu \mathrm{L}$ de $\mathrm{NH}_{4} \mathrm{Cl}(25 \% \mathrm{~m} / \mathrm{v})$ e colocados em provetas. Estas misturas foram passadas pelas colunas redutoras, sendo os primeiros $7 \mathrm{~mL}$ descartados. Para determinação dos íons na solução eluída restante foram 
tomados $5 \mathrm{~mL}$. A estes foram adicionados $100 \mu \mathrm{L}$ da solução R1 e $100 \mu \mathrm{L}$ da solução R2. As transmitâncias foram determinadas após $10 \mathrm{~min}$ a $543 \mathrm{~nm}$.

Método em estudo: Determinação de microquantidades de nitrato e nitrito ${ }^{2}$

\section{Curva padrão para nitrato}

Foi preparada uma solução padrão de nitrato de potássio contendo $148 \mu \mathrm{g} \mathrm{mL}^{-1} \mathrm{NO}_{3}^{-}\left(0,2415 \mathrm{~g} \mathrm{~L}^{-1}\right.$ de nitrato de sódio, previamente seco em estufa à $100{ }^{\circ} \mathrm{C}$ ). Foram retiradas alíquotas de 50 , $80,100,150,180,200,260,280$ e $300 \mu \mathrm{L}$ para balões volumétricos de $25 \mathrm{~mL}$ (soluções padrão). Foram adicionados $0,5 \mathrm{~mL}$ de ácido clorídrico $2 \mathrm{M}, 0,6 \mathrm{~mL}$ de resorcinol e $6,5 \mathrm{~mL}$ de ácido sulfúrico concentrado. Após $30 \mathrm{~min}$, os volumes nos balões foram completados com água e as transmitâncias das soluções foram determinadas a $505 \mathrm{~nm}$.

\section{Curva padrão para nitrito}

Foi preparada uma solução padrão de nitrito de potássio contendo $666 \mu \mathrm{g} \mathrm{NO}_{2}^{-} / \mathrm{L}\left(1 \mathrm{~g} \mathrm{~L}^{-1}\right.$ de nitrito de potássio previamente seco durante $1 \mathrm{~h}$ em estufa à $100^{\circ} \mathrm{C}$ ). Foram retiradas alíquotas para preparo dos padrões de $15,30,45,60,75,95 \mu \mathrm{L}$ para balões volumétricos de $50 \mathrm{~mL}$. Foram adicionados $1 \mathrm{~mL}$ de hidróxido de sódio $2 \mathrm{M} ; 6 \mathrm{~mL}$ de $\rho$-nitroanilina, após $15 \mathrm{~min} 4 \mathrm{~mL}$ de $\alpha$-naftilamina e após $5 \mathrm{~min}$ $10 \mathrm{~mL}$ de CTMAB. Os volumes nos balões foram completados com água, agitados e as transmitâncias medidas a $530 \mathrm{~nm}$.

\section{Determinação de nitrato nas amostras}

Para determinação de nitrato foram utilizados $25 \mathrm{~mL}$ das amostras, $1 \mathrm{~mL}$ de ácido clorídrico $2 \mathrm{M} ; 1,2 \mathrm{~mL}$ de resorcinol e $13 \mathrm{~mL}$ de ácido sulfúrico concentrado. Após $30 \mathrm{~min}$, as misturas foram diluídas com água a $50 \mathrm{~mL}$ e as transmitâncias lidas a $505 \mathrm{~nm}$.

\section{Determinação de nitrito nas amostras}

Para determinação de nitrito foram utilizados $25 \mathrm{~mL}$ das amostras, $1 \mathrm{~mL}$ de hidróxido de sódio $2 \mathrm{M}, 6 \mathrm{~mL}$ de $\rho$-nitroanilina, repouso $15 \mathrm{~min}, 4 \mathrm{~mL}$ de $\alpha$-naftilamina (repouso $5 \mathrm{~min}$ ) e $10 \mathrm{~mL}$ de CTMAB. As misturas foram agitadas, avolumadas com água a 50 $\mathrm{mL}$ e as transmitâncias medidas a $530 \mathrm{~nm}$.

\section{Avaliação da performance dos métodos}

A avaliação da recuperação do íon nitrato foi realizada adicionando-se 6, 12 e $18 \mathrm{mg}$ do padrão de $\mathrm{KNO}_{3}$ a três amostras de pele de peixe porco torrada a $130{ }^{\circ} \mathrm{C}$ durante 30 min e três amostras de pele crua, que foram submetidas à extração com solução de sulfato de amônio.

Para o íon nitrito foi realizada adicionando-se 1, 2 e $3 \mathrm{mg}$ do padrão de $\mathrm{KNO}_{2}$ a três amostras de pele de peixe porco torrada a $130{ }^{\circ} \mathrm{C}$ durante 30 min e três amostras de pele, crua submetidas à extração com solução de sulfato de amônio.

As determinações das concentrações dos íons nestas soluções foram realizadas segundo os procedimentos do método oficial e do método em estudo.

Os limites de detecção para os dois métodos em estudo foram estimados através da determinação das transmitâncias das provas em branco. Os procedimentos foram repetidos 6 vezes. Os desvios padrão das absorbâncias foram calculados, multiplicados por 3, sendo os limites de detecção estimados nas respectivas curvas padrão ${ }^{15,16}$.

\section{Determinações estatísticas}

Os resultados dos procedimentos foram comparados estatisticamente através de análise de variância e teste de Tukey empregando o software Statistic 5.0 no modo ANOVA/MANOVA.

\section{RESULTADOS E DISCUSSÃO}

Na Tabela 1 estão apresentados os resultados das quantificações dos íons nitrato e nitrito que foram determinados nas amostras constituídas de peles cruas extraídas, conforme o método oficial e o alternativo, e as tostadas, por $30 \mathrm{~min}$, à 130 e $160^{\circ} \mathrm{C}$, extraídas sob refluxo aquoso durante $30 \mathrm{~min}$, empregando-se procedimentos espectrofotométricos recomendados pelos dois métodos para quantificação. O método oficial ${ }^{12,14}$ recomenda como solvente de extração uma solução aquosa de sais de cádmio e bário e requer a redução de nitrato a nitrito usando colunas redutoras de amalgama de cádmio. $\mathrm{O}$ método de Guozhen et al. ${ }^{11}$ determina separadamente cada ânion e pode empregar solução de sulfato de amônio para a extração, denominado método alternativo neste trabalho.

Tabela 1. Resultados médios das determinações de nitrato e nitrito em peles de peixe porco e papa-terra empregando os métodos oficial e alternativo

\begin{tabular}{lcccc}
\hline Amostras & \multicolumn{2}{c}{ Método oficial (mg/100g) } & \multicolumn{2}{c}{ Método alternativo (mg/100g) } \\
& Nitrito & Nitrato & Nitrito & 0,28 \\
Nitrato \\
\hline PP(sulfato) & 0,32 & 1,08 & 0,39 & 2,08 \\
PP (cloretos) & 0,47 & 2,21 & 0,46 & 1,85 \\
PP (30') & 0,35 & 2,10 & 0,34 & 2,45 \\
PP (60') & 0,33 & 2,00 & 0,65 & 1,40 \\
PPT (sulfato) & 0,80 & 1,20 & 1,03 & 2,05 \\
PPT (cloretos) & 1,09 & 2,15 & 0,37 & 3,40 \\
PPT (30') & 0,45 & 4,48 & 0,54 & 2,55 \\
PPT (60') & 0,43 & 1,8 & \\
\hline
\end{tabular}

PP (sufato): pele de peixe porco/extração com sulfato de amônio; PP(cloretos): pele de peixe porco/extração com cloreto de cádmio; PP (30'): pele de peixe porco torrada a $160{ }^{\circ} \mathrm{C}$ por $60 \mathrm{~min} /$ refluxo aquoso $30 \mathrm{~min}$; $\mathrm{PP}\left(60\right.$ '): pele de peixe porco torrada a $160{ }^{\circ} \mathrm{C}$ por $60 \mathrm{~min} /$ refluxo aquoso $60 \mathrm{~min}$. PPT (sulfato) pele de peixe papa-terra/extração com sulfato de amônio; PPT (cloretos): pele de peixe papa-terra/ extração com cloreto de cádmio; PPT (30’): pele torrada de peixe papa-terra torrada a $160{ }^{\circ} \mathrm{C}$ por $60 \mathrm{~min} / \mathrm{refluxo}$ aquoso 30 min; PPT(60'): pele torrada de peixe papa-terra/refluxo aquoso $60 \mathrm{~min}$. 
Os resultados da Tabela mostram que as quantidades de nitrato são superiores às de nitrito, nas diferentes condições de extração e quantificação, atingindo valores até 8 vezes maiores. Tal se justifica pelo fato do nitrato ser a forma oxidada mais estável do nitrogênio. As concentrações de nitrito só aumentam em baixos níveis de oxigênio, onde ocorre a redução do nitrato (denitrificação) ou durante a biodegradação de nitrato ou nitrogênio amoniacal ${ }^{8,11,12}$.

Os valores médios das quantidades de nitrato e nitrito nas peles cruas das duas espécies, determinados pelos dois métodos foram de 1,69 e $1,70 \mathrm{mg}$ nitrato/100 g e 0,37 e 0,89 mg nitrito/100 g para peles de peixe porco e papa-terra, respectivamente. Cabe salientar que os resultados dos teores de nitrato para as duas espécies foram sempre superiores quando se realizava extração com cloreto de cádmio, especialmente no método oficial.

Quando foram determinados os íons nos extratos aquosos obtidos sob refluxo, os valores médios encontrados foram 2,58 e 3,06 $\mathrm{mg}$ de nitrato/100 g e 0,37 e $0,46 \mathrm{mg}$ de nitrito/100 g, respectivamente, para peles de peixe porco e papa-terra. Neste caso os resultados encontrados pelos dois métodos diferiram menos entre si e o coeficiente de variação entre eles ficou em torno de $16 \%$. Isto mostra que a extração dos íons nas peles cruas é fortemente influenciada pelo sistema extrator, com uma tendência a ter seus valores do ânion nitrato mais elevado quando se emprega solução de cloreto de cádmio.

A comparação com as informações disponíveis na literatura mostra que os resultados diferem dos mencionados por Gangolli et al. ${ }^{6}$ $1,1 \mathrm{mg} / 100 \mathrm{~g} \mathrm{e} 0,12 \mathrm{mg} / 100 \mathrm{~g}$ para nitrato e nitrito no músculo de pescados. Mesmo que no estudo as espécies e as porções estudadas tenham sido de outras espécies, as diferenças encontradas não levam a questionar os valores encontrados nas determinações realizadas.

Monser et al. ${ }^{8}$ determinaram nitrito em músculo de sardinha através da oxidação de um complexo azul de fosfomolibdênio e nitrato com o auxílio de colunas redutoras de cádmio. Seus resultados foram de 3,8 e 3,4 mg/100 g para nitrato e nitrito, respectivamente. Os valores de nitrato encontrados em pele de papa-terra neste trabalho, extraído sob refluxo durante 30 min e determinado pelo método alternativo, foi semelhante ao mencionado pelos autores. Trata-se de uma coincidência, pois nas demais condições de extração e quantificação foram muito diferentes, o que é decorrente das diferenças entre as espécies e da porção utilizada para a determinação.

Os dados da Tabela 1 foram comparados estatisticamente utilizando análise de variância, a 5\% de significância, onde foi verificado que pelo menos um dos tratamentos para a determinação de nitrato e nitrito diferiu. Portanto, foi realizado um teste de diferenças de médias estatística, o teste de Tukey a 5\% de significância, para se avaliar a diferença entre os tratamentos.

Na Figura 1 estão ilustrados os resultados do teste de Tukey para o conteúdo de nitrato e nitrito em pele de peixe porco. A Figura 2 mostra o resultado do teste para a pele de papa-terra.

Os resultados obtidos para o íon nitrito determinado em pele de peixe porco crua mostraram que a extração empregando solução extratora 1 (cloretos) difere significativamente dos demais pelo método oficial e pelo método em estudo. No entanto, após o tratamento térmico das peles, as respostas obtidas pelo método oficial ou pelo alternativo não diferiram significativamente, indicando que os resultados foram afetados pelo sistema de preparo da amostra e não pela reação química empregada para a quantificação. O mesmo caso foi observado para a pele de papa-terra, onde os resultados para as outras formas de extração diferiram do obtido com a solução extratora 1 significativamente, o que não ocorreu com as peles tratadas termicamente. Assim como no caso anterior, os dados reforçam que a diferença entre a quantificação pelos métodos alternativo e oficial decorre da etapa de extração e preparo da amostra e não pelo sistema quantitativo.
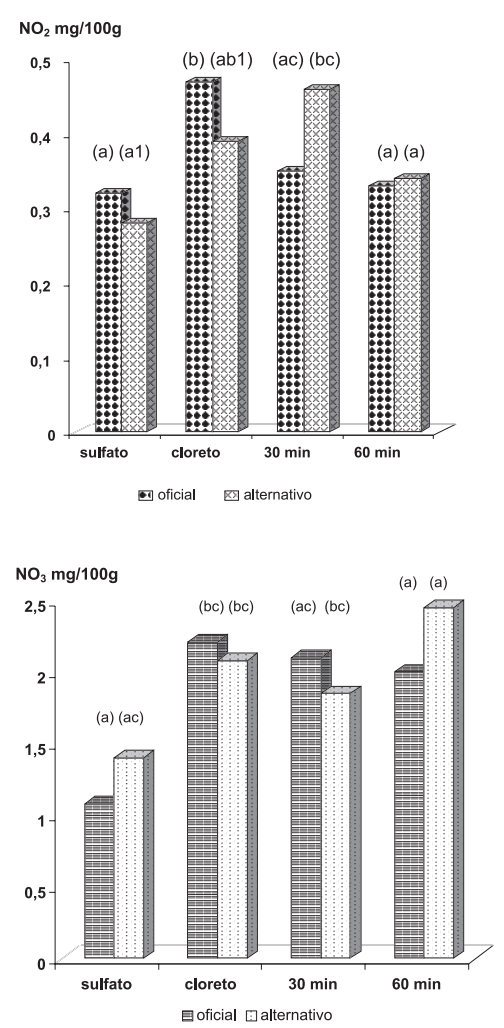

Figura 1. Resultados dos teores de nitrato e nitrito obtidos pelos diferentes sistemas de extração e quantificação e suas significâncias em pele de peixe porco. Pelo menos 1 letra repetida significa que os tratamentos não têm diferença significativa a $5 \%$ e número repetido significa que o tratamento tem diferença significativa a 5\%. Sulfato (extração com sulfato); cloreto (extração com cloreto de cádmio); $30 \mathrm{~min}$ (pele torrada à $160^{\circ} \mathrm{C}$ e refluxada por $30 \mathrm{~min}$ ); $60 \mathrm{~min}$ (pele torrada à $160^{\circ} \mathrm{C}$ e refluxada por $60 \mathrm{~min}$ ); oficial (determinação pelo método oficial); alternativo (determinação pelo método alternativo)

No caso do íon nitrato as diferenças entre os sistemas de preparo de amostra e sistemas extratores reforçam o observado para o nitrito, sempre com a tendência dos métodos não diferirem significativamente nos seus resultados quando a pele foi tostada.

O sistema extrator que emprega solução de sais de cloretos é desvantajoso quando se consideram os descartes de resíduos ao final das determinações, além do proveniente das colunas redutoras no processo de regeneração. Outro aspecto que chamou a atenção foi que os valores encontrados para íon nitrito, independentemente do reagente de derivação empregado, foram sempre maiores quando se empregava a solução extratora 1, sugerindo que o nitrato pode estar sendo reduzido já durante a etapa de extração em solução de cloreto de cádmio.

Estes dados foram bastante promissores, pois se o método alternativo não difere do oficial, quando não se emprega extração com soluções de cloreto de cádmio, ele pode ser empregado para avaliar o efeito do tratamento térmico nos íons nitrato e nitrito nos chás das peles de pescados consumidos pela população.

Para corroborar com estas observações os dois métodos foram comparados quanto aos limites de detecção e recuperação empregando peles cruas e torradas de peixe porco. Os resultados são mostrados na Tabela 2.

$\mathrm{O}$ autor do método em estudo ${ }^{11}$ mencionou uma recuperação média de $96 \%$ para nitrato e $97 \%$ para nitrito em estudo em água potável. Os resultados neste caso foram semelhantes a estes e aos 

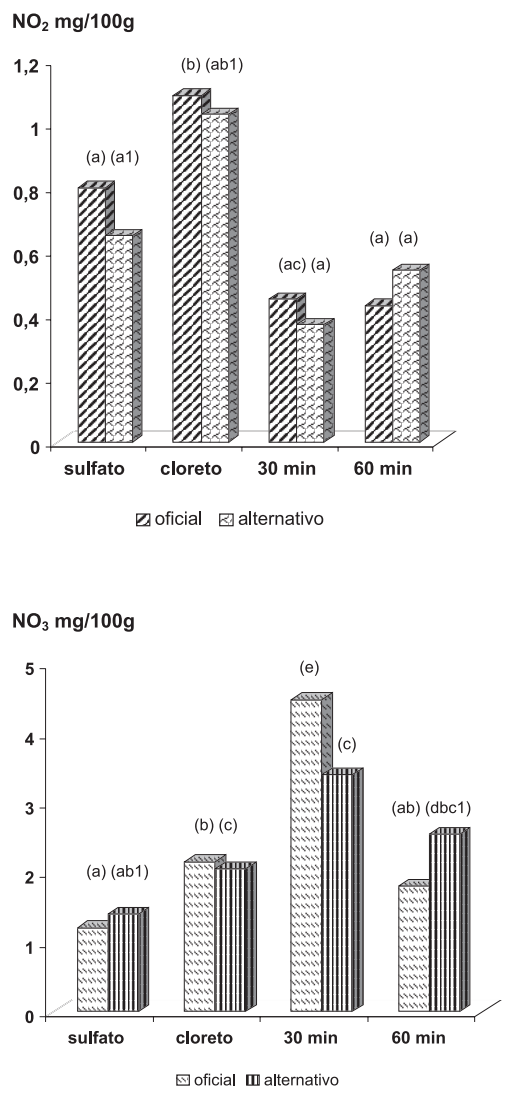

Figura 2. Resultado dos teores de nitrato e nitrito obtidos pelos diferentes sistemas de extração e quantificação e suas significâncias em pele de papaterra. Pelo menos 1 letra repetida significa que os tratamentos não têm diferença significativa a 5\% e número repetido significa que o tratamento tem diferença significativa a 5\%. Sulfato (extração com sulfato); cloreto (extração com cloreto de cádmio); $30 \mathrm{~min}$ (pele torrada à $160^{\circ} \mathrm{C}$ e refluxada por $30 \mathrm{~min}$ ); $60 \mathrm{~min}$ (pele torrada à $160^{\circ} \mathrm{C}$ e refluxada por $60 \mathrm{~min}$ ); oficial (determinação pelo método oficial); alternativo (determinação pelo método alternativo)

do método oficial sendo, portanto, aplicáveis às determinações em soluções aquosas, como é o caso das amostras deste trabalho (chás).

Quanto ao limite de detecção observa-se que o método em estudo apresentou um limite de detecção 10 vezes menor para o íon nitrato que o método oficial. Quanto ao nitrito, os resultados de ambos foram próximos.

Considerando-se que o preparo doméstico das peles e dos chás nem sempre é facilmente controlável, o método alternativo foi escolhido para avaliar o efeito do tratamento térmico nos teores dos íons quando as peles são tratadas à 130 e $160{ }^{\circ} \mathrm{C}$ por 30 e $60 \mathrm{~min}$ para as duas temperaturas. Estas diferentes combinações de tempo e temperatura visaram abranger as possibilidades de variação que podem ocorrer domesticamente no preparo dos chás.

Na Figura 3 pode-se observar que os níveis de nitrito mantiveram uma tendência à constância com a variação da temperatura e o tempo de torra na pele de peixe porco. No caso do papa-terra, a temperatura de tostagem e o tempo de refluxo provocaram maiores variações nos teores deste ânion. Possivelmente isto se deva ao fato de que o nitrito não é a forma mais estável dos óxidos de nitrogênio sendo, portanto, mais afetado pela temperatura de tostagem e pela composição da matriz. Esta diferença é demonstrada pelo teor de cinzas encontrado para as duas peles, 11 e $1 \%$, respectivamente, de peixe porco e papa-terra. A maior variação
Tabela 2. Indicativos de mérito dos métodos em comparação

\begin{tabular}{lcccc}
\hline & \multicolumn{3}{c}{ Método oficial } & \multicolumn{3}{c}{ Método alternativo } \\
& $\mathrm{NO}_{3}{ }^{-}$ & $\mathrm{NO}_{2}^{-}$ & $\mathrm{NO}_{3}^{-}$ & $\mathrm{NO}_{2}^{-}$ \\
\hline L. detecção $(\mu \mathrm{M})$ & 0,05 & 0,01 & 0,005 & 0,02 \\
Recup. pele crua $(\%)$ & 93 & 95 & 100 & 97 \\
Recup. pele torrada(\%) & 97 & 95 & 98 & 96 \\
\hline
\end{tabular}

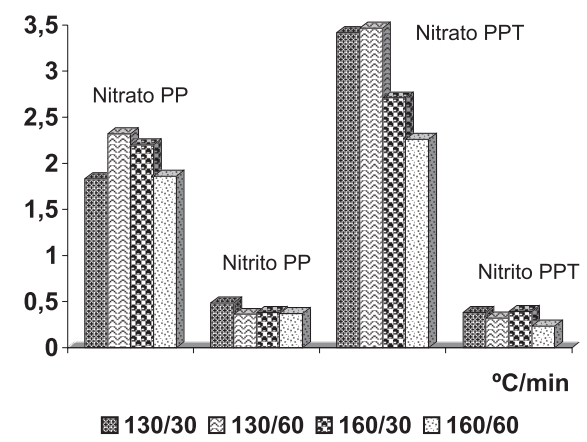

Figura 3. Influência da temperatura e do tempo de torração na concentração de nitrato e nitrito determinados pelo método alternativo. Nitrato PP: conteúdo de nitrato em pele de peixe porco torrada; nitrito PP: conteúdo de nitrito em pele de peixe porco torrada; nitrato PPT: conteúdo de nitrato em pele de papa-terra torrada; nitrito PPT: conteúdo de nitrito em pele de papaterra torrada

nos teores de nitrato em função da temperatura também ocorreu na pele de papa-terra, indicando a influência da composição da matriz durante o tratamento térmico.

Um outro aspecto importante destes resultados é a indicação que o método alternativo pode detectar variações nas concentrações dos íons ocasionadas pelas condições de preparo.

A partir dos resultados encontrados nas condições testadas, sob o aspecto segurança para consumo humano, pode-se estimar o risco decorrente do consumo dos chás considerando-se as informações do "Safety Committee for Food (SCF)" da Inglaterra. Este recomenda uma ingestão diária alimentar máxima (IDA) de 1,08 g do íon nitrato e $1,8 \mathrm{mg}$ do íon nitrito para adultos de $60 \mathrm{~kg}^{6}$. As quantidades de nitrato e nitrito que variaram entre 1,5 a $3 \mathrm{mg} / 100 \mathrm{~g}$ e 0,35 a $0,7 \mathrm{mg} /$ $100 \mathrm{~g}$, respectivamente, estão abaixo desta recomendação.

Segundo as informações dos consumidores a quantidade utilizada no preparo do chá contra os problemas respiratórios é de $2 \mathrm{~g}$ de pele seca e moída por L/dia, para um homem adulto de $70 \mathrm{~kg}$ $(0,03 \mathrm{~g} / \mathrm{kg})$. Isto equivale a um consumo de 0,03 a $0,06 \mathrm{mg}$ de $\mathrm{NO}_{3}^{-}$ e 0,007 a $0,014 \mathrm{mg}$ de $\mathrm{NO}_{2}{ }^{-}$, ou seja, valores bem abaixo do recomendado. Além disso, Cavalli ${ }^{2}$, em testes de toxicidade com ratos machos Wistar, demonstrou que doses de $2,8 \mathrm{~g} / \mathrm{kg}$ de extrato aquoso de pele de Balistes capriscus, o que equivale a 93,3 vezes o consumido por um homem adulto de $70 \mathrm{~kg}$, não provocaram sinais visíveis de toxicidade ou mortalidade em nenhuma das cobaias.

\section{CONCLUSÃO}

A comparação entre os resultados e a performance dos métodos oficial e alternativo mostrou que este pode ser empregado para determinação do conteúdo de nitrato e nitrito em peles cruas e em chás de peles torradas. O método de Guozhen et al. ${ }^{11}$ neste trabalho teve um limite de detecção 10 vezes mais baixo para o íon nitrato que o método oficial. Quanto ao nitrito, os resultados de ambos 
foram semelhantes. As recuperações para os métodos também apresentaram valores próximos a $100 \%$.

$\mathrm{O}$ consumo diário de $2 \mathrm{~g}$ de pele seca e moída para um homem adulto de $70 \mathrm{~kg}(0,03 \mathrm{~g} / \mathrm{kg})$ equivale, de acordo com os valores encontrados, a um consumo de 0,03 a $0,06 \mathrm{mg}$ de $\mathrm{NO}_{3}^{-}$e 0,007 a $0,014 \mathrm{mg}$ de $\mathrm{NO}_{2}$. Considerando os limites recomendados como seguros para consumo, um chá preparado com esta quantidade de pele não ocasionaria danos à saúde dos usuários.

\section{REFERÊNCIAS}

1. Cavalli, L. S.; Dissertação de Mestrado, Fundação Universidade Federal do Rio Grande, Brasil, 2002.

2. CEPERG/RS (Centro de Pesquisa e Gestão dos Recursos Pesqueiros Lagunares e Estuarinos) - IBAMA; Desembarque de Pescados no Rio Grande do Sul, Rio Grande, 1999, 2000, 2001.

3. Costello, J.; Annals of N. Y. Acad. Sc. 1991, 629, 7.

4. Filho, R. F.; Zilberstein, B.; Rev. Assoc. Med. Bras. 2000, 46, 1.
5. Ignarro, L. J.; An. Ver. Pharm. Toxic. 1990, 30, 535.

6. Gangolli, S. D.; Brandt, P. A.; Feron, V. J.; Janzowsky, C.; Koeman, J. H.; Speijers, G. J. A.; Spiegelhalder, B.; Walker, R.; Wishnok, J. S.; Envirom. Toxicol. Pharmacol. 1994, s 00, 1.

7. L 'Hirondel, J.; L 'Hirondel, J. L.; Nitrate and Man: Toxic, Harmless or Beneficial?, France: Hardback, 2001.

8. Monser, L.; Sadok, S.; Greenway, G. M.; Shah, I.; Uglow, R. F., Talanta 2002, 57, 511.

9. Moorcroft, M. J.; Davis, J.; Compton, R. G.; Talanta 2001, 54, 785.

10. Mikuska, P.; Vecera, Z.; Anal. Chim. Acta 2003, 495, 225.

11. Guozhen, P.; QingI, X.; Mei, F.; Microchem. J. 1998, 60, 258.

12. Baumgarten, M. G. Z.; Rocha, J. M. B.; Nienchesk, L. F. H.; Manual de Análises em Oceanografia Química, Rio Grande: Ed. da FURG, 1996.

13. Til, H. P.; Falke, H. E.; Kuper, C. F.; Willems, M. I.; Food Chem. Toxicol. 1988, 26, 851.

14. AOAC Internacional; Official methods of analysis, Ed. Arlington, $17^{\text {th }}$ ed., 2000.

15. Caulcutt, R.; Boddy, R.; Statistics for Analytical Chemists, USA: Chapman and Hall, $2^{\text {nd }}, 1983$

16. Ribani, M.; Quim. Nova 2004, 27, 771. 